\title{
El buen ambiente de aprendizaje. ¿Cómo lograrlo?
}

Ma. Ofelia Béjar López Peniche

$\mathrm{E}$ 1 objetivo de todo profesor es lograr que sus estudiantes aprendan. Sin embargo, tener clara la meta no es suficiente, pues el proceso de enseñanza y aprendizaje involucra infinidad de elementos que han de tomarse en cuenta para obtener los resultados deseados. Por ello, en este artículo se reflexiona en concreto sobre el ambiente de aprendizaje que se da cuando el profesor y el estudiante coinciden en un salón de clases y "se ven obligados" a interactuar en un mismo espacio, lo cual genera emociones, sentimientos y actitudes entre ambos actores educativos.

El salón de clases es el espacio físico para la construcción significativa de la cultura y los saberes (Sauvé, 1994). Es un espacio de encuentro y en el que conviven tanto profesores como estudiantes, con diversas características, personalidades, intereses y formas de sentir, producto de sus propias interacciones sociales formales e informales, lo que sin duda tendrá efectos sobre el aprendizaje (Biggs, 2005).

Es necesario considerar estos rasgos y cualidades para establecer relaciones interpersonales básicas y positivas entre maestros y alumnos (Duarte: 2005). Un salón de clases muy bien equipado, un profesor muy bien preparado y/o el interés común por la materia a enseñar y aprender, no son elementos suficientes para crear un ambiente favorable para el aprendizaje. Éste surgirá a partir de la relación y vínculo que se establezca desde el principio del curso entre profesor y estudiantes. El vínculo positivo llevará, sin duda, a mejores resultados.

¿Qué entender por ambiente de aprendizaje?

La pedagogía crítica ve a la escuela como el lugar que permite al estudiante afirmarse y autotransformarse (Mclaren, 1984), y para lograrlo, es necesario crear un buen ambiente de aprendizaje.

Cada profesor, como cada institución en su conjunto, crea un clima de aprendizaje mediante las interacciones formales e informales con los alumnos. Este clima tiene que ver con la forma en que ellos y nosotros tenemos de sentir las cosas y esto, naturalmente, tiene efectos positivos o negativos sobre su aprendizaje (Biggs, 2010: 87).

El clima o ambiente de aprendizaje va más allá de un espacio físico, incluye las relaciones humanas; involucra al ser humano, a las acciones pedagógicas y hace del salón de clases un espacio para la construcción de la cultura, la reflexión so- bre las propias acciones y las acciones de los demás, lo que deriva en la interacción del hombre con su entorno natural (Duarte, 2005).

\section{¿Cómo lograr un buen ambiente para un buen} aprendizaje?

Un buen ambiente de aprendizaje es "abierto, participativo, ideal, coherente y propicio para la formación integral del educando desde el punto de vista académico, social, emocional y con más oportunidades para la convivencia armónica" (Molina, 2006), es aquél en el que prevalecen relaciones interpersonales de respeto, confianza, diálogo y comprensión entre todos los integrantes del grupo.

De acuerdo a lo anterior, Boekaerts (2001, citado en Díaz Barriga, 2010: 69) señala: 
En el contexto áulico, los estudiantes son especialmente sensibles a los significados emocionales de sus experiencias académicas y de manera similar, sus profesores experimentan emociones que se relacionan con procesos cognitivos y motivacionales de los que depende su eficacia docente. Los profesores interactúan a diario con estudiantes que experimentan una variedad de emociones e involucrar a los estudiantes en el aprendizaje requiere de experiencias emocionales positivas y consistentes.

Con base en lo anterior, para lograr un buen ambiente de aprendizaje y una positiva interacción con los estudiantes, no basta con encontrarse en el mismo salón de clases. Hay que crear desde el inicio un vínculo, una buena relación que facilite el proceso. Para esto, es necesario un profesor respetuoso, cercano, congruente en el establecimiento de normas claras, capaz de mantener el orden en el grupo, de aplicar las sanciones acordadas y de establecer parámetros de evaluación adecuados; preocupado por el estudiante y comprometido con su aprendizaje al darle retroalimentación clara y oportuna.

El vínculo involucra la afectividad de profesores y estudiantes, pues se trata de personas con pensamientos y sentimientos. Inicia cuando el profesor se preocupa por saber quiénes son sus estudiantes, los identifica por su nombre, conoce su interés o desinterés por la materia, escucha sus opiniones y toma en cuenta sus sentimientos y creencias. ${ }^{1}$ El estudiante, al sentirse aceptado, identificado y valorado en su persona por el profesor y en un ambiente de confianza, respeto y cordialidad, desarrollará naturalmente un interés y compromiso por participar, expresarse e involucrarse con su propio proceso de aprendizaje. Al respecto, Giroux (1992) afirma que:

Es muy importante que los estudiantes entiendan que las diferencias culturales, étnicas, raciales e ideológicas incrementan la posibilidad de diálogo, la sinceridad y la solidaridad. Las diferencias deben ser analizadas y estructuradas dentro de unos contextos pedagógicos que fomenten la

1 Esto no significa que deba conocer la vida del estudiante y mucho menos que se convierta en su gran amigo. compasión y la tolerancia en lugar de la envidia, el odio y la intolerancia.

Por lo tanto, en la medida en la que profesores y estudiantes se sientan cómodos dentro del aula que compartan, se logrará un ambiente agradable y de apertura que favorecerá el aprendizaje y motivará al estudiante a preguntar, participar, trabajar con otros estudiantes y discutir los contenidos.

\section{Otros elementos para el buen ambiente de aprendizaje}

Además de crear el vínculo con el estudiante, es muy importante desde el inicio del curso establecer y dialogar sobre las normas orientadas a favorecer el logro de los objetivos y asegurarse que sean conocidas por todos, al igual que las consecuencias por no cumplirlas.

Asimismo, el profesor ha de mantener en la clase una actitud positiva, trato cordial y respetuoso hacia los estudiantes, promover activamente la participación de éstos, motivarlos y connotarlos de forma positiva después de sus intervenciones, mostrarse dispuesto para resolver dudas con voluntad, mantener siempre la disciplina, en congruencia con las normas acordadas, y manejar situaciones conductuales irregulares (Arón y Milicic, 2000).

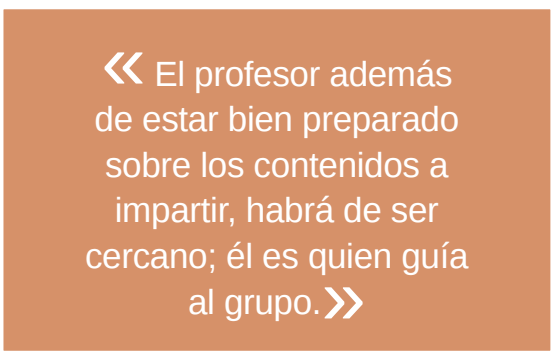

Otro elemento que no puede dejar de mencionarse para el buen clima, es la claridad y congruencia de los elementos a evaluar. Será de gran importancia que desde el inicio del curso, el profesor enuncie con claridad la forma de evaluación, haga rúbricas, las explique y las proporcione al estudiante antes de realizar algún trabajo; así como entregarle evaluaciones claras y congruentes con las referidas rúbricas, igualmente de manera oportuna, de forma tal que le permita medir sus logros y hacer las mejoras pertinentes para llegar al final del curso con un aprendizaje significativo y exitoso. 
Finalmente, es un reto constante para todo profesor despertar y mantener el interés de los estudiantes en la asignatura, y aunque sin duda las estrategias, los contenidos y la experiencia del profesor son importantes, lo es también, como se ha reflexionado, la relación que existe entre profesor y estudiante y entre los mismos estudiantes.

Si desde el inicio se logra crear un vínculo positivo y se trabaja por un ambiente adecuado, el curso fluirá y se obtendrán mejores resultados, pues es un hecho que los aspectos afectivos -emociones y sentimientos-, se relacionan con la metacognición y la autorregulación del estudiante para el aprendizaje (García, 2009). En este contexto, plantear expectativas desafiantes y viables para los alumnos y promover que tengan confianza en su propia capacidad y en su inserción social como profesionista, es indispensable para motivar al estudiante (Universidad Iberoamericana, 2013).

\section{Conclusiones}

De acuerdo con lo expuesto, el ambiente de aprendizaje es una construcción del profesor y los estudiantes dentro del aula que involucra varios aspectos, de los cuales, en este artículo se ha reflexionado sobre los que específicamente se refieren al vínculo o relación entre el profesor y los estudiantes; pues es importante para el profesor contar con un buen grupo, y para el grupo, con un buen profesor.

El profesor, además de estar bien preparado en los contenidos a impartir, habrá de ser cercano pero no invasivo, y no olvidar que él es quien guía al grupo, por ello, no debe convertirse en un amigo o compañero, ha de ser respetuoso con los estudiantes y conducirlos al aprendizaje con firmeza y congruencia, sin saltarse o aplicar las normas "según su humor", y siempre ha de ser claro con las evaluaciones y retroalimentaciones.

El salón de clases es un espacio de encuentro entre personas con diferentes formas de ser, pensar y actuar, un espacio en el que convive la diversidad, y lo importante es lograr en conjunto un ambiente agradable para aprender y compartir la riqueza de todos los que lo integran.
Fuentes de consulta

Arón, A. y Milicic, N. (2000). Climas sociales tóxicos y climas sociales nutritivos para el desarrollo personal en el contexto escolar. Revista Psyke, 9(2). Chile: Pontificia Universidad Católica de Chile.

Biggs, J. (2005). Calidad del aprendizaje universitario. Madrid: Narcea.

Díaz Barriga, F. (2010). Estrategias docentes para un aprendizaje significativo. Una interpretación constructivista. México: Mc Graw Hill.

Duarte, J. (2005). Ambientes de aprendizaje, una aproximación conceptual. Revista Iberoamericana de Educación. Colombia: Organización de Estados Iberoamericanos. Recuperado el 31 de mayo de 2016, en: http://rieoei.org/rec_dist1.htm.

García, B. (2009). Las dimensiones afectivas de la docencia. Revista Digital Universitaria. México: UNAM-DGSA. Recuperado el 31 de mayo de 2016, en: http://bit.ly/2dKR1O1.

Giroux, H. (1992). Educación y ciudadanía para una democracia crítica. Más allá de la ética de lo trivial. Revista Aula de Innovación Educativa 1. Barcelona: Editorial Graó. Recuperado el 21 de octubre de 2016, en: http://bit.ly/2eGH8T9.

Mclaren, P. (1984). La vida en las escuelas. Una introducción a la pedagogía crítica en los fundamentos de la educación. México: Siglo XXI. Recuperado el 19 de octubre de 2016, en: http://bit.ly/1Je4Axm.

Molina, N. y Pérez, I. (2006) El clima de relaciones interpersonales en el aula. Un caso de estudio. Revista Paradigma, 27(2). Recuperado el 2 de junio de 2016, en: http://bit. ly/2fegEwV.

Sauvé, L. (1994). Exploración de la diversidad de conceptos y de prácticas en la educación relativa al ambiente. Memorias Seminario Internacional. La dimensión ambiental y la escuela. Serie Documentos Especiales. Colombia: Ministerio de Bogotá.

Universidad Iberoamericana (2013). Ayuda Pedagógica. México: UI. 